\title{
Anabases
}

ANABASES Traditions et réceptions de l'Antiquité

9 | 2009

Varia

\section{Odile CAVALIER (dir.), Le voyage en Grèce du comte de Choiseul-Gouffier}

\section{Adeline Grand-Clément}

\section{OpenEdition}

\section{Journals}

Édition électronique

URL : http://journals.openedition.org/anabases/564

DOI : 10.4000/anabases.564

ISSN : 2256-9421

\section{Éditeur}

E.R.A.S.M.E.

\section{Édition imprimée}

Date de publication : 1 mars 2009

Pagination : 321-322

ISSN : 1774-4296

\section{Référence électronique}

Adeline Grand-Clément, "Odile cavalier (dir.), Le voyage en Grèce du comte de Choiseul-Gouffier », Anabases [En ligne], 9 | 2009, mis en ligne le 01 juillet 2011, consulté le 21 septembre 2020. URL: http://journals.openedition.org/anabases/564 ; DOI : https://doi.org/10.4000/anabases.564

Ce document a été généré automatiquement le 21 septembre 2020.

(c) Anabases 


\title{
Odile CAVALIER (dir.), Le voyage en Grèce du comte de Choiseul-Gouffier
}

\author{
Adeline Grand-Clément
}

\section{RÉFÉRENCE}

Odile CAVALIER (dir.), Le voyage en Grèce du comte de Choiseul-Gouffier, Avignon-Le Pontet, Fondation Calvet-Éditions Barthélémy, 2007, 159 p., 30 euros / ISBN 978-2-87923-246-1.

1 L'ouvrage, édité à l'occasion d'une exposition présentée au musée Calvet du 30 juin au 5 novembre 2007, est consacré à la personnalité complexe du comte Marie-GabrielFlorent-Auguste de Choiseul-Gouffier (1752-1817). Cet aristocrate érudit, passionné par la Grèce ancienne, a largement contribué à la promotion de l'hellénisme en France, à la fin de l'Ancien Régime. Un premier voyage initiatique en Grèce et en Asie Mineure en 1776 , suivi d'un long séjour à Constantinople, en tant qu'ambassadeur de France auprès des Ottomans, de 1784 à 1792, lui permettent d'amasser dessins et relevés de sites et de publier un Voyage pittoresque de la Grèce dont le dernier volume paraît à titre posthume (1782-1824). Avec l'aide d'agents dévoués, comme Fauvel, et d'un dense réseau de relations consulaires dans les Échelles, il parvient également à se doter d'une très belle collection d'antiques, particulièrement riche en marbres grecs. Exilé en Russie en 1792, il ne retrouve la jouissance de ce patrimoine exceptionnel que lors de son retour en France, en 1802 : sur l'ordre du Premier consul, la majeure partie des pièces confisquées par les révolutionnaires lui est alors restituée. À sa mort, ses héritiers procèdent à la vente de la collection, dont le Louvre devient l'un des principaux acquéreurs.

2 Les huit articles qui forment la matière principale du livre reviennent ainsi sur le parcours, l'œuvre et les voyages de Choiseul-Gouffier; ils mettent aussi en lumière le rôle joué par certains membres de son entourage et dressent l'histoire des antiquités qu'il avait soigneusement "collectées». Chaque étude, accompagnée d'une riche documentation iconographique, s'appuie sur d'abondantes citations de lettres, 
manuscrits, inventaires et catalogues d'archives provenant de fonds très variés. Vassiliki Gaggadis-Robin commence par retracer les principaux jalons de la vie de l'aristocrate, notamment sa première exploration du sol hellénique, « un Homère et un Hérodote à la main », en 1776. Il souligne l'importance de son Voyage pittoresque, qui devient vite un ouvrage de référence pour les philhellènes et les savants français. Géraud Poumarède s'efforce ensuite de reconstituer dans le détail l'itinéraire du premier voyage en Grèce, ainsi que le trajet du retour, par l'Italie, à la lumière de documents inédits. Pierre Pinon et Annie Gilet proposent de courtes notices sur deux de ses compagnons de voyage, artistes engagés à son service : l'architecte et ingénieur Jacques Foucherot, le dessinateur Louis-François Cassas. Alessia Zambon consacre pour sa part une étude fort suggestive à un autre agent du comte, sans doute le plus actif: Louis-François-Sébastien Fauvel. Elle souligne le rôle déterminant qu'il joue dans la constitution de la vaste collection d'antiquités grecques, issues de fouilles, achetées ou acquises de façon illégale. Vassiliki Gaggadis-Robin et Marianne Hamiaux s'attachent alors à relater l'histoire mouvementée des pièces ainsi amassées en Méditerranée orientale. Expédiées et stockées à Marseille, puis confisquées pendant la Révolution, certaines œuvres enrichissent les fonds du musée de Marseille et y demeurent, en dépit de la restitution exigée en 1802. D'autres rejoignent les salles du musée du Louvre et en deviennent même l'un des fleurons, telle la plaque de la frise des Ergastines, provenant du Parthénon. Les nombreux moulages effectués par Fauvel à la demande du comte connaissent, semble-t-il, un destin différent. Christiane Pinatel prend ainsi l'exemple de sept plaques en plâtre, reproduisant les cavaliers de la frise du Parthénon, que l'on retrouve dans la galerie de la serre du château de la Malmaison, construit pour l'impératrice. La première partie du volume, complétée par un long ex-cursus généalogique sur la famille des Choiseul-Gouffier, s'achève avec la postface de Françoise et Roland Étienne: une synthèse indispensable, qui offre au lecteur une excellente mise en perspective historique de l'œuvre et de la personnalité du comte, un homme finalement davantage tourné vers l'Ancien Régime que vers le XIX ${ }^{e}$ siècle. Les deux dernières parties du livre, de taille beaucoup plus réduite, recèlent des compléments d'information: reproductions miniatures et courtes notices des œuvres présentées lors de l'exposition ; annexes comprenant une solide bibliographie et l'index des noms de personnes citées. Une carte, permettant de localiser les principales étapes des voyages de Choiseul-Gouffier et de ses agents, ainsi qu'une chronologie détaillée de la vie du comte, mise en regard avec la riche actualité historique de son temps, auraient sans doute mérité d'y figurer.

3 L'intérêt majeur du volume réside dans la pluralité des éclairages jetés sur la figure $d u$ comte. On ne doit point se borner à y voir un "érudit, ambassadeur et philhellène ", comme le proclame volontiers Vassiliki Gaggadis-Robin dans sa présentation: l'étude passionnante d'Alessia Zambon, ainsi que l'excellente mise au point de Françoise et Roland Étienne viennent en effet nuancer ce portrait élogieux en soulignant la part active prise par le comte dans l'entreprise de pillage systématique de la Grèce dénoncé par Byron. En témoigne l'une des lettres adressées à Fauvel, qui s'occupe de ses affaires à Athènes: "Enlevez tout ce que vous pourrez, ne négligez aucun moyen, mon cher Fauvel, de piller dans Athènes et dans son territoire, tout ce qu'il y a de pillable. » L'avidité de Choiseul-Gouffier ne procède pas seulement d'un souci de conservation des œuvres, qu'il faudrait arracher aux barbares turcs : la constitution d'une importante collection d'antiques est aussi pour lui un instrument de prestige et de pouvoir, un moyen d'affirmer son statut social élevé. Cela fait de lui un philhellène d'un genre un 
peu particulier, souvent plein de mépris pour les Grecs modernes, qui ressemblent si peu à leurs glorieux ancêtres. Le volume permet en outre de suivre presque pas à pas, de façon très vivante, le voyage mouvementé accompli par les objets antiques, depuis leur découverte ou leur collecte en Méditerranée orientale, jusqu'à leur réception en France. «Réparées » par d'audacieux restaurateurs ou au contraire " amincies », afin de faciliter leur transport ou leur exposition, la plupart des œuvres achèvent leur parcours dans les musées ou chez de riches collectionneurs. On voit ainsi s'esquisser les contours d'un réseau complexe d'échanges, dont la configuration évolue au gré du contexte national et international: c'est l'âge d'or du trafic d'antiquités, activité fort lucrative, organisée à grande échelle et souvent orchestrée par le pouvoir politique.

\section{AUTEURS}

\section{ADELINE GRAND-CLÉMENT}

Université de Toulouse (UTM)

adelinegc@yahoo.fr 